\title{
Cementless Zweymüller Hip Replacement: A Short-Term Follow-Up in Al Razi Hospital, Kuwait
}

\author{
Wieslaw Pospula Tarek Abu Noor Ahmad Al Rowaih \\ Department of Orthopedics, Al Razi Hospital, Kuwait
}

\section{Key Words}

Cementless hip replacement $\cdot$ Clinical and radiological results

\begin{abstract}
Objective: To present initial experience of the first 71 cases of cementless total hip replacement in Al Razi Hospital. Subject and Methods: Between 1996 and 2004, total hip replacement was performed in 71 patients $(40$ male, 31 female, average age 40.7 years, range 17-74) using Zweymüller cementless prosthesis. The patients were followed clinically and radiologically over an average period of 36 months (range 6-84). The results were assessed according to Merle d'Aubigne clinical score. Radiological assessment included position of the implant, behavior of the prosthesis/bone interface and signs of osteointegration. Results: Average clinical score during the 3 years' follow-up period was 17.8 points. Most of the implants were in optimal positions. No significant radiological modifications of the implant-bone interface were observed. Conclusion: Zweymüller total hip prosthesis gives excellent clinical and radiological results in short-term follow-up.
\end{abstract}

Copyright $(2005$ S. Karger AG, Basel

\section{Introduction}

Total hip replacement (THR) introduced in clinical practice in the middle of the previous century has revolutionized the treatment of painful hip arthritis in adults. Initial success of cemented designs has been overshadowed by an increased rate of loosening in younger patients due to a number of factors related to cement fractures $[1,2]$. Loosening of the prosthetic components and excessive polyethylene wear were the most common problems in patients younger than 50 years [3]. Therefore, an alternative solution of fixing the prosthesis without cement has been sought. The designs and materials used in THR have undergone significant evolution during the last 3 decades with high success rate of implants in current use [4]. Uncemented acetabular and femoral components with titanium as a structural element of the prosthesis because of its biocompatibility, with different materials as a prosthetic bearing, are in common use. We are reporting our preliminary results of 71 patients who underwent THR with titanium cementless Zweymüller prosthesis.

\begin{tabular}{ll}
\hline KARGER & ( ) 2005 S. Karger AG, Basel \\
Fax +4161306 1234 $34-7571 / 05 / 0144-0255 \$ 22.00 / 0$ \\
$\begin{array}{l}\text { E-Mail karger@karger.ch } \\
\text { www.karger.com }\end{array}$ & $\begin{array}{l}\text { Accessible online at: } \\
\text { www.karger.com } / \mathrm{mpp}\end{array}$
\end{tabular}




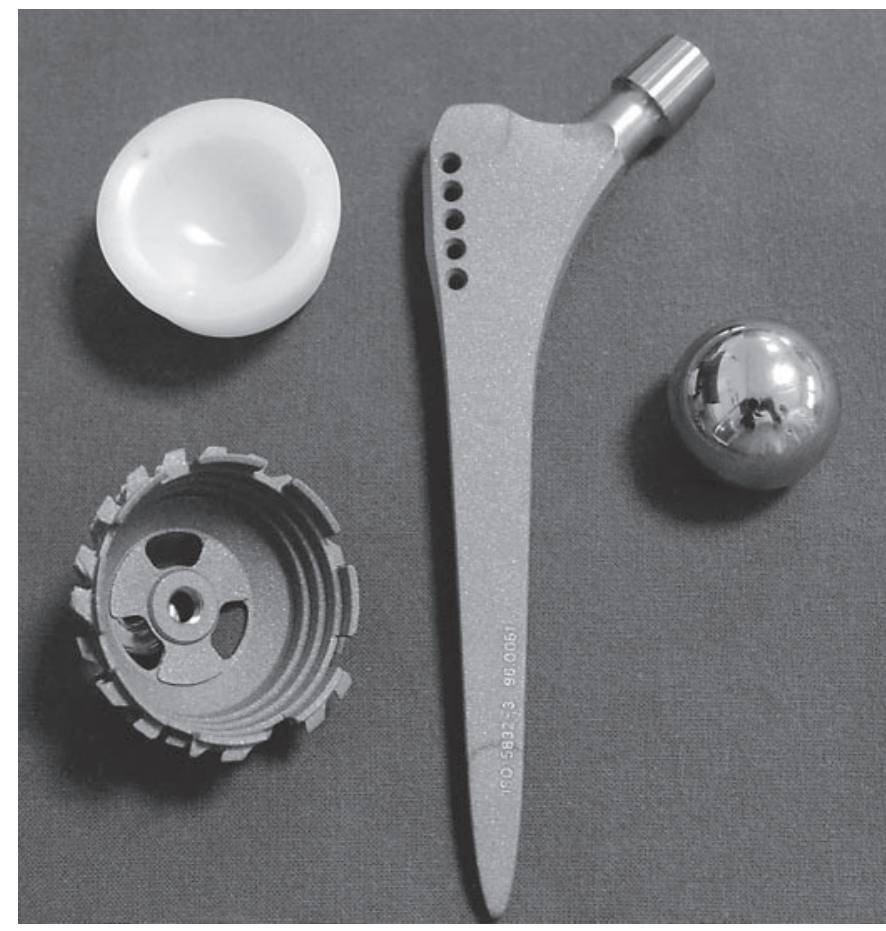

Fig. 1. General view of the modular cementless Zweymüller hip prosthesis.

\section{Subjects and Methods}

Between 1996 and 2004, THR was performed in 71 patients in Al Razi Hospital, Kuwait using the Zweymüller cementless prosthesis. Of the patients 40 were male and 31 female with an average age of 40.7 years (range 17-74 years). Average follow-up period was 36 months (range 6-84 months). The most common indications for surgery were idiopathic and secondary avascular necrosis of the femoral head; 12 and 23, respectively. The other indications were: primary and secondary coxarthrosis, $\mathrm{n}=12$; rheumatoid arthritis, $\mathrm{n}=8$; developmental dysplasia of the hip, $\mathrm{n}=3$, and femoral neck fracture and its complications, $n=13$. Zweymüller prosthesis, a titanium cementless femoral implant and the threaded cup with polyethylene insert were used in all cases. The straight titanium tapered femoral stem (fig. 1) was press-fitted without cement in all cases. Operations were performed from direct transgluteal approach (30 cases) and modified Watson Jones approach (41 cases) by the senior author (W.P.).

Patients were scored clinically according to Merle d'Aubigne hip score [5] before the operation, 3-6 months, 1 year and every year after the THR. Pain, ability to walk and range of movements were estimated with a 6-point scale. Standard anteroposterior and lateral X-ray of the pelvis and operated hip were performed at each follow-up examination.

For the radiological assessment, the geometrical position of components, and migration and changes in the prosthesis-bone interface were evaluated.

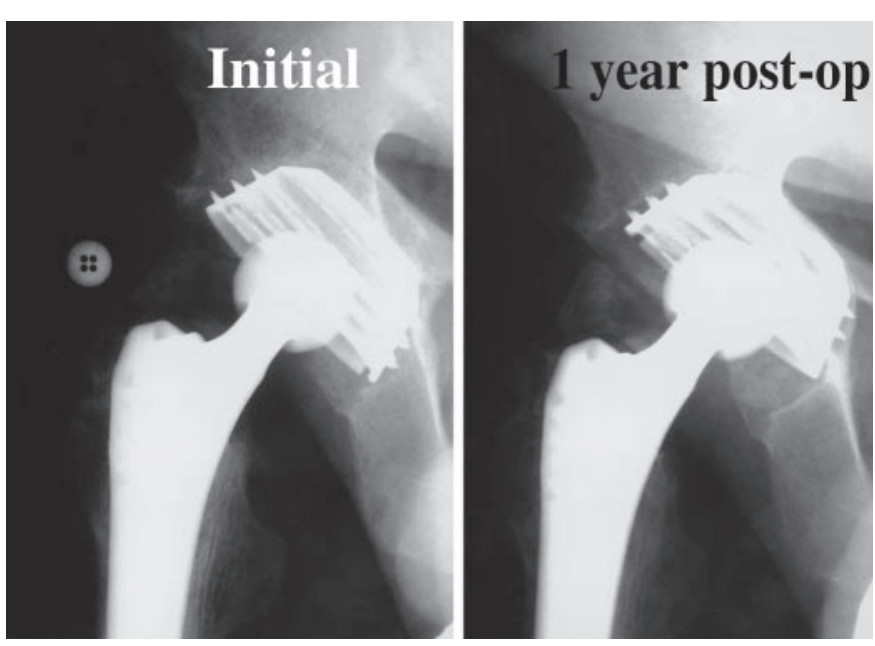

Fig. 2. Migration of the acetabular component of the prostheses during 1-year observation.

\section{Results}

The average hip score was 17.8 points out of 18 as a maximum score at the average follow-up of 36 months. No difference was observed in the hip score of both approaches. The patients improved in all aspects of the clinical picture. Initial excellent or good primary acetabular fit was achieved in all but 1 case. Initial excellent or good femoral fit was achieved in all cases.

Inclination of the prosthetic cup was within the desired range $\left(30-50^{\circ}\right)$ in $58(81.7 \%)$ cases; horizontal (below $30^{\circ}$ ) in $1(1.4 \%)$ case and vertical (above $50^{\circ}$ ) in $6(9.2 \%)$ cases. Sixty-one $(85.9 \%)$ prosthetic cups were implanted in anteverted position, $3(4.2 \%)$ in mild retroversion and 1 $(1.4 \%)$ in neutral position. Prosthetic stem was implanted in neutral position in 44 cases $(62 \%)$, in varus position in $11(15.5 \%)$ cases and in valgus position in $6(8.5 \%)$ cases. Version of the stem was not assessed.

The implant-prosthesis interface did not show any lucency in $98 \%$ of the acetabular components. No visible changes in bone adjacent to the implant were observed in most cases. In 1 case significant migration of the prosthetic cup with circumferential lucency (fig. 2) was seen. 
Fig. 3. Reactive lines in zones I and VII and distal cortical hypertrophy with pedestal.

Fig. 4. Calcar atrophy during 3 years' observation.

Fig. 5. Bone remodeling of the acetabular floor during 2 years' observation.
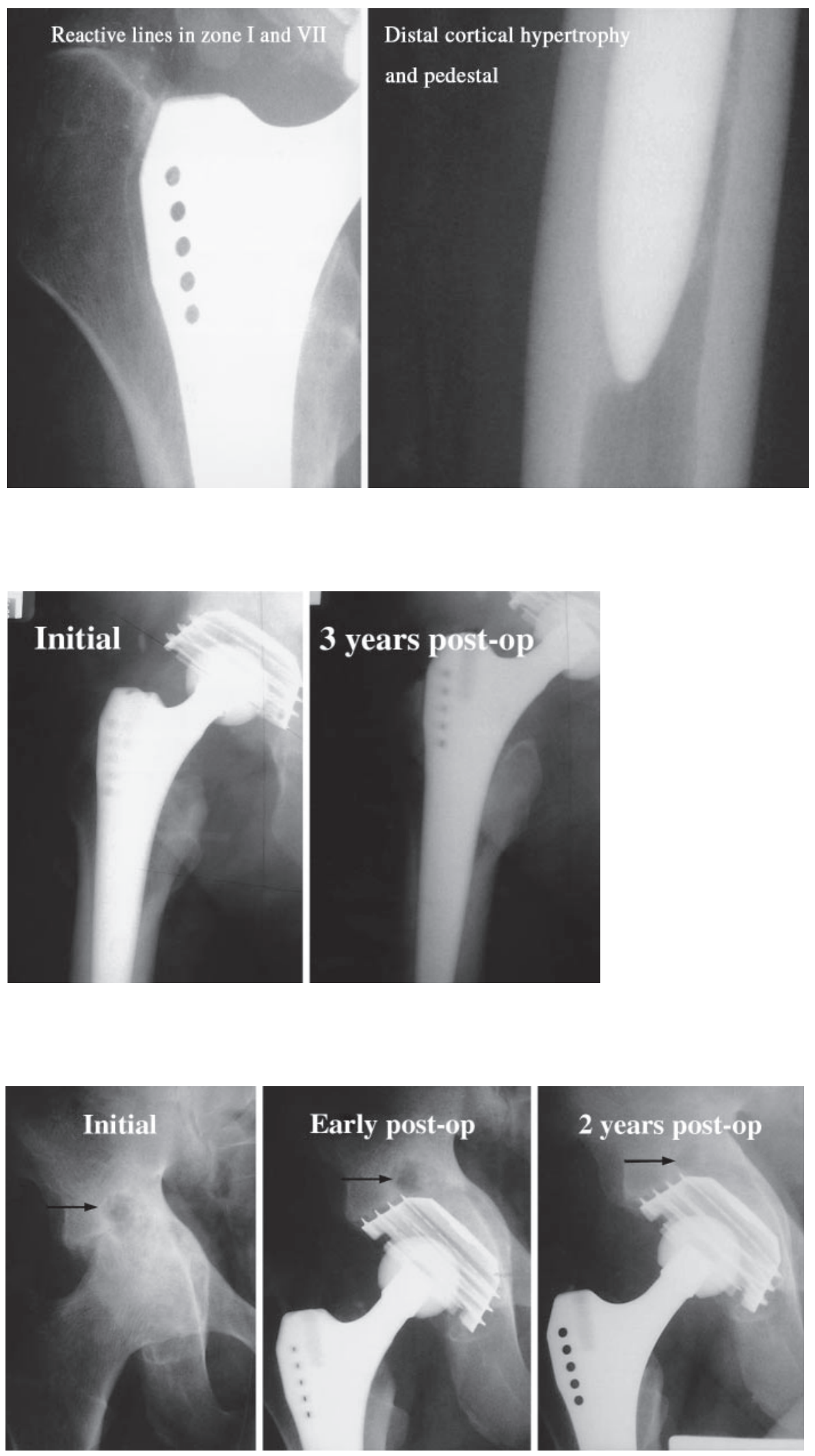
No significant changes in the prosthesis-bone interface in the femur were observed. In 3 cases reactive lines and pedestal distal to the prosthesis were seen (fig. 3). In 11 cases there was evidence of calcar atrophy denoting a stress shielding phenomenon (fig. 4). In 7 patients cancellous bone graft was used to reinforce the acetabular floor and it was compressed by the threaded cup during screwing-in. In all the cases good remodeling of the graft of the acetabular floor was observed (fig. 5).

Complications entailed 1 case of deep infection that necessitated staged revision, 1 case of transient femoral palsy on the operated side that recovered after 6 weeks, 1 case of deep vein thrombosis and nonfatal embolism and 2 cases of dislocation. In 1 patient the dislocation was due to insufficient soft tissue tension; the hip stabilized after closed reduction and hip spica for 6 weeks. In the second case it was due to vertical position of the cup, that stabilized on conservative treatment.

\section{Discussion}

Cementless THR became a standard procedure for treatment of primary and secondary osteoarthritis of the hip in young individuals while cemented prostheses are advocated in the elderly patients [6]. The longevity of the result is assured by osteointegration of the implant. Once the prosthesis is integrated it remains so for an extended period of time. Our short-term clinical results are as excel- lent as in other studies [7, 8]. However, the number of cases in our sturdy is small compared with others and it reflects the relative rarity of coxarthrosis in Kuwait [9]. Although concern about the threaded cup has been expressed in a number of studies [10,11], we did not encounter significant problems compared to the other published series using the same type of implant [11-14]. Within 3 months of surgery, most patients did not feel any pain, they had good walking capacity and range of movement of the hip. Anterior thigh pain, commonly seen in cementless stem in many studies, was present only in 2 cases. This is attributable to the excellent primary frontal and rotary stability provided by the prosthesis design, taper and rectangular shape as reported in previous studies $[15,16]$.

Modifications of bone structure around the prosthesis as a reaction to load distribution were observed in our cases similar to those noted by previous authors $[17,18]$. No correlation between periprosthetic bone modification and the clinical result was observed similar to other studies $[19,20]$.

\section{Conclusion}

Total hip replacement using Zweymüller prosthesis gives excellent clinical and radiological results during an average period of 36 months. There are no significant radiological modifications of the prosthetic/bone interface. The complication rate was low.

\section{References}

1 Davies JP, Harris WH: Tensile bonding strength of the cement-prosthesis interface. Orthopedics 1994; 17:171-173.

-2 Lu Z, McKellop H: Effects of cement creep on stem subsidence and stresses in the cement mantle of a total hip replacement. J Biomed Mater Res 1997;34:221-226.

>3 Smith SE, Estok DM, Harris WH: 20-year experience with cemented primary and conversion total hip arthroplasty using so-called second-generation cementing techniques in patients aged 50 years or younger. J Arthroplasty 2000;15:263-273.

-4 Kim YH, Oh SH, Kim JS: Primary total hip arthroplasty with a second-generation cementless total hip prosthesis in patients younger than fifty years of age. J Bone Joint Surg 2003; 85A:109-114.

5 Merle d'Aubigne R, Postel M: Functional results of hip arthroplasty with acrylic prosthesis. J Bone Joint Surg 1954;76A:129-138.
6 Keisu KS, Orozco F, Sharkey PF, Hozack WJ, Rothman RH: Primary cementless total hip arthroplasty in octogenarians: Two to elevenyear follow-up. J Bone Joint Surg 2001; 83A:359-363.

$>7$ Delaunay C, Kapandji AI: 115 primary implantations of Karl Zweymüller's acetabular screw rings after a follow-up of an average of 5.8 years. Rev Chir Orthop Reparatrice Appar Mot 1994;80:388-402.

$>8$ Delaunay CP, Kapandji AI: Survivorship of rough-surfaced threaded acetabular cups: 382 consecutive primary Zweymüller cups followed for 0.2-12 years. Acta Orthop Scand 1998;69:379-383.

9 Pospula W, Al-Rowaih A, Hussein T: Total hip replacement in Kuwait: Preliminary results of Exeter hip prosthesis and remarks on ethnic and causative factors. KMJ 2000;32:281284
10 Aldinger PR, Thomsen M, Lukoschek M, Mau $\mathrm{H}$, Ewerbeck V, Breusch S: Long-term fate of uncemented, threaded acetabular components with smooth surface treatment: Minimum 10year follow-up of two different designs. Arch Orthop Trauma Surg 2004;124:469-475.

11 Fink B, Protzen M, Hansen-Algenstaedt N, Berger J, Ruther W: High migration rate of two types of threaded acetabular cups. Arch Orthop Trauma Surg 2004;124:17-25.

12 Delaunay CP, Kapandji AI: Acetabular screw rings and surface treatment. Clin Orthop 1997; 340:130-141.

13 Delaunay C, Cazeau C, Kapandji AI: Cementless primary total hip replacement: Four to eight year results with the Zweymuller-Alloclassic prosthesis. Int Orthop 1998;22:1-5.

14 Effenberger H, Ramsauer T, Dorn U, Imhof $\mathrm{M}$ : Factors influencing the revision rate of Zweymueller acetabular cup. Int Orthop 2004; 28:155-158. 
15 Bonnomet F, Delaunay C, Simon P, Lefebvre Y, Clavert P, Kapandji AI, Kempf JF: Straight femoral taper in cementless primary total hip replacement in $<65$ year-old patients: Multicenter study of 115 consecutive implantations at mean 8.2 year follow-up. Rev Chir Orthop Reparatrice Appar Mot 2001;87:802-814.

16 Huo MH, Martin RP, Zatorski LE, Keggi KJ: Total hip arthroplasty using the Zweymuller stem implanted without cement: A prospective study of consecutive patients with minimum 3-year follow-up period. J Arthroplasty 1995; 10:793-799.
17 Ang KC, Das De S, Goh JC, Low SL, Bose K: Periprosthetic bone remodelling after cementless total hip replacement: A prospective comparison of two different implant designs. J Bone Joint Surg 1997;79B:675-679.

8 Sumner DR, Turner TM, Igloria R, Urban RM, Galante JO: Functional adaptation and ingrowth of bone vary as a function of hip implant stiffness. J Biomech 1998;31:909-917.
9 Duparc J, Pospula WM, Grzegorczyk AZ, Losicki M, Koty W: Radiological image of the femur after cementless total hip replacement in a 3-years' follow-up. Ann Univ Mariae Curie Sklodowska [Med] 1993;48:95-101.

20 Wilhelm K, Conrad R, Reich H, Zieger H, Schild H: Radiologic changes following cement-free implantation of hip prostheses: 5year follow-up and clinical experience with the cement-free hip prosthesis Autophor-900-S Aktuelle Radiol 1998;8:225-231. 